THE EFFECT OF STRUCTURAL DEFECTS IN SiC PARTICLES ON THE STATIC AND DYNAMIC MECHANICAL RESPONSE OF A 15 VOLUME PERCENT SiC/6061-Al MATRIX COMPOSITE

\begin{tabular}{|c|c|}
\hline Author(s): & $\begin{array}{l}\text { R. U. Vaidya } \\
\text { S. G. Song } \\
\text { A. K. Zurek } \\
\text { G. T. Gray III }\end{array}$ \\
\hline
\end{tabular}

Submitted to:

\author{
APS Topical Conference on Shock \\ Compression of Condensed Matter, 1995
}

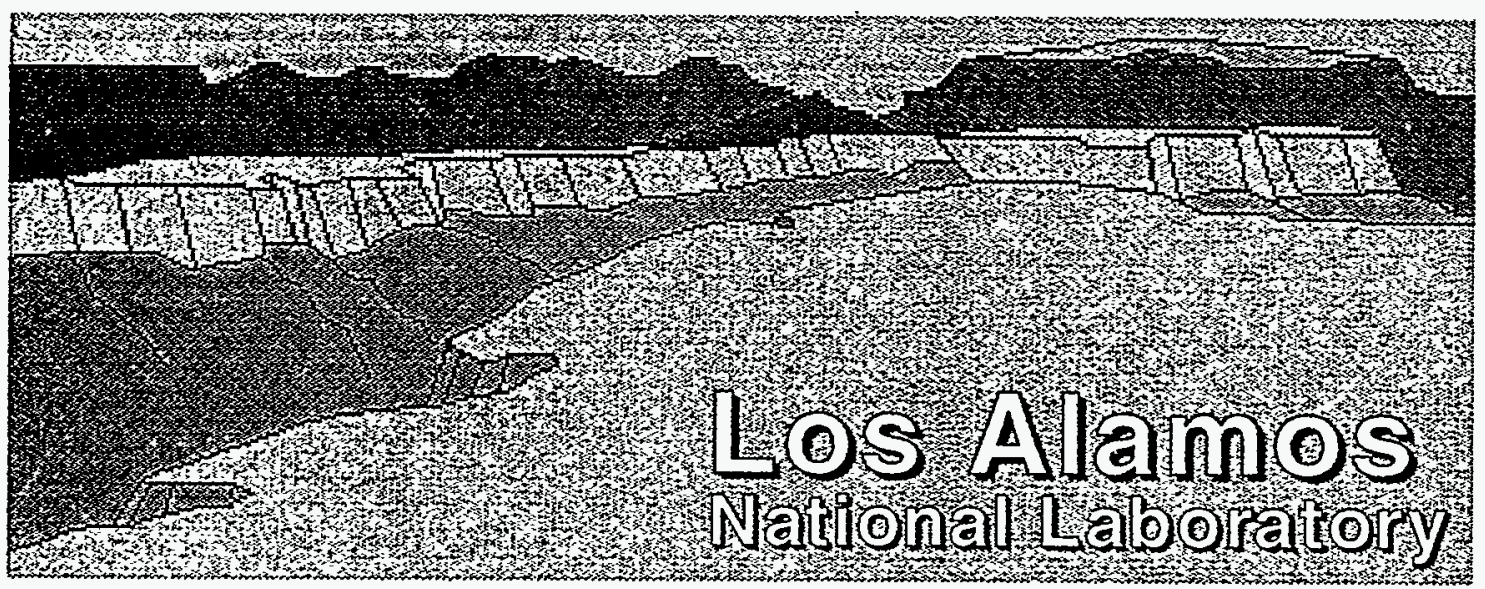

Los Alamos National Laboratory, an affirmative action/equal opportunity employer, is operated by the University of California for the U.S. Department of Energy under contract W-7405-ENG-36. By acceptance of this article, the publisher recognizes that the US. Govermment retains a nonexclusive, tree license to publish or reproduce the published form of this contribution, or to allow others to do so, for U.S. Govemment pumoses. The Los National Laboratory requests that the publisher identify this article as work performed under the auspices of the U.S. Department of Energy.

This is a preprint of a paper intended for publication in a journal or proceedings. Because changes may be made before publication, this preprint is made avallable with the understanding that it will not be cited or reproduced without the permission of the author. 


\section{DISCLAIMER}

Portions of this document may be illegible in electronic image products. Images are produced from the best available original document. 


\title{
THE EFFECT OF STRUCTURAL DEFECTS IN SiC PARTICLES ON THE STATIC \& DYNAMIC MECHANICAL RESPONSE OF A 15 VOLUME PERCENT SiC/6061-AI MATRIX COMPOSITE
}

\author{
R. U. Vaidya, S. G. Song, A. K. Zurek, and G. T. Gray III \\ Materials Science \& Technology, Los Alamos National Laboratory, Los Alamos, New Mexico 87544
}

Static and Dynamic mechanical tests, and microstructural examinations performed on a $\mathrm{SiC}$ particle reinforced 6061-Al matrix composite indicated that particle cracking significantly affected the strength, strain hardening, and failure mechanism of the composite. Cracks were observed to nucleate and propagate on stacking faults and interfaces between the various phases within the reinforcing $\mathrm{SiC}$ particles. Planar defects were the predominant artifacts seen in the $\mathrm{SiC}$ particles. Partial dislocations were also observed bounding the stacking faults within the réinforcement phase.

\section{INTRODUCTION}

Aluminum matrices reinforced with ceramic particles such as $\mathrm{SiC}$ and $\mathrm{Al}_{2} \mathrm{O}_{3}$ have been studied extensively because of their potential technological advantages over conventional aluminum alloys. These advantages include higher stiffness, wear resistance, and creep resistance over the alloys on which they are based [1-3]. Although the mechanical properties of these composite materials have been extensively studied and documented in litcrature, many recent studies have focused on correlating the observed properties to the properties of the constituents of the composite system viz. the matrix, reinforcements, and the interface. Changes in the propertics of the components of the composite system can have a significant effect on the overall properties of the compositc.

Our present study focuses on a 15 volume percent SiC particle reinforced Al 6061 matrix compositc. The strength of the composite in icnsion and compression was significantly lower as compared to the value predicted by a volume fraction rule. We have correlated the observed mechanical behavior of the composite to stacking falults and other defects within the $\mathrm{SiC}$ particles.

\section{GXPERIMENTAL PROCEDURE}

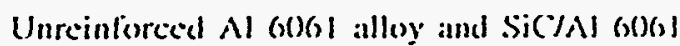
composite samples were obtatined in the lorm of spraty cast extruded rods. 1 cm in diameter and iso) $\mathrm{cm}$ long. The aluminum alloy was a commercial grade alloy, and had the following composition: $\mathrm{Al}$ $+1.0 \% \mathrm{Mg}+0.6 \% \mathrm{Si}+0.28 \% \mathrm{Cu}$. The nominal volume fraction of the $\mathrm{SiC}$ particles was $15 \%$, and the average size of the $\mathrm{SiC}$ particles was $15 \mu \mathrm{m}$. The particles asperity along the extruded direction was neglected since all of the samples were machined along that direction. All of the samples were annealed in air for 12 hours in a box furnace prior to testing.

Quasistatic and dynamic compression tests were performed on cylindrical samples, having a diameter of $0.5 \mathrm{~cm}$ and a height of $0.5 \mathrm{~cm}$. The quasistatic compression tests were performed in an Instron machine, at a strain rate of $10^{-3} \mathrm{~s}^{-1}$, while tho dynamic compression tests were performed using a Split Hopkinson pressurc bar at $6500 \mathrm{~s}^{-1}$. Quasistatic tensile tests were also performed on samples having a gage length of $1.25 \mathrm{~cm}$ and gage diameter of $0.4 \mathrm{~cm}$, in an Instron machinc, all a strain ratc of $10^{-3} \mathrm{~s}^{-1}$.

Samples used for transmission electron microscopy (TEM) observations were prepared by dimpling $3 \mathrm{~mm}$ dises. followed by ion milling. TFM observations were conducted in a lhillips ( $M$ 30 mictoscupe.

\section{RESLILTS AND DISCUSSION}

Results of the compression and lension lests ate shown in tigures 1. 2 and 3. Allowngh the olastic 
modulus of the composite samples was significantly enhanced over the unreinforced alloy samples, the composite samples fractured at significantly smaller strains in tension as compared to the unreinforced alloy. Furthermore, the compression strain hardening for the composite samples was not significantly enhanced as compared to the unreinforced alloy samples.

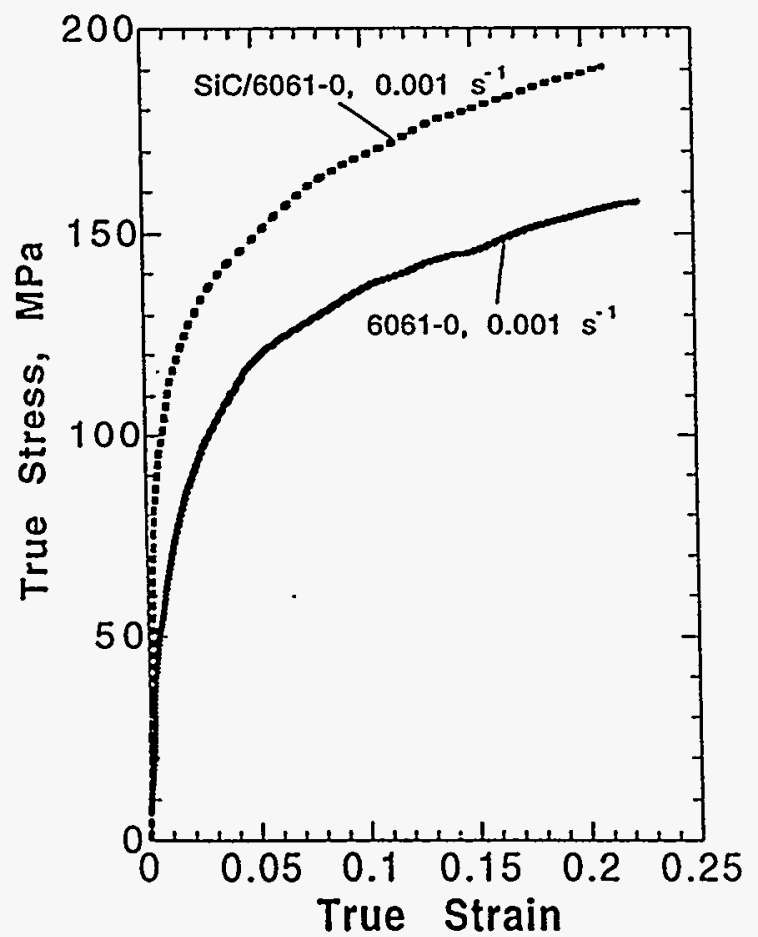

FIGURE 1. Compression responses for the unreinforced 6061 alloy and $\mathrm{SiC} / 6061$ compositc samples at $10^{-3} \mathrm{~s}^{-1}$.

A simplified volume fraction rule when used to calculate the theoretical tensile strength of the composite, gave a value of $171.5 \mathrm{MPa}$. The experimentally observed value was $147 \mathrm{MPa}$. Discrepancies between the experimental and theorelical strength values were resolved on the hasis of fractographic observations conducted on the composite samples. Scanning electron microscony (Figure 4) carried out on the fractured composite surlaces exhibited the presence of extensive particle matrix debonding. This dehonding was altributed to the wetling characteristics of the $\mathrm{SiC}$ particles by the molen aluminum alloy |+t-6). Cracked Sic particles were also observed on the polished surfates of the fractured composite samples, Figure 5. The nature of the cracking process was unclear, because the theoretical fracture strength of the $\mathrm{SiC}$ particles is significantly higher as compared to the strength of the aluminum matrix alloy [7].

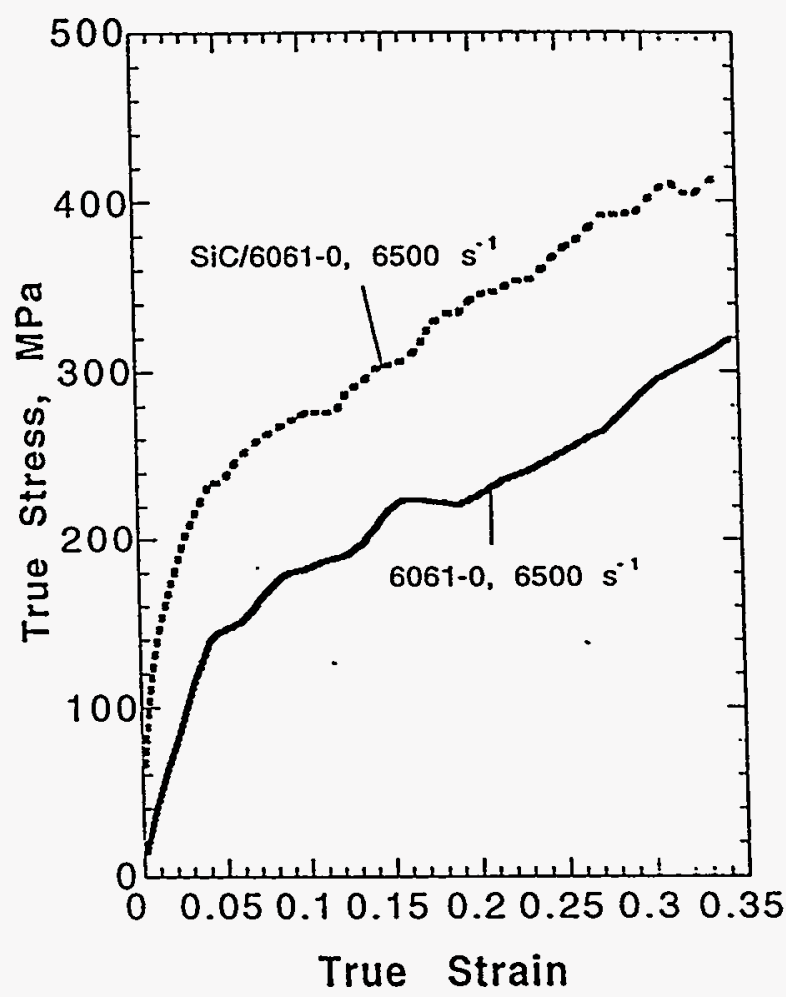

FIGURE 2. Compression responses for the unreinforced 6061 alloy and $\mathrm{SiC} / 6061$ compositc samples at $6500 \mathrm{~s}^{-1}$.

Transmission clcctron microscony (TEM) was carricd out to ascertain the nature of the particle cracking. The TEM micrograph in Figure 6 shows microcracks initiated within the reinforcing SiC particles. The microcracks appeared to propalgatte on specific planes within the particles. These planes were also observed to he parallel to one anesther. Detailed TEM analysis revealed that the cracking within the SiC particles oceurred along stacking fatuls between various phatses within the particles: |8|. The vast majority of the stacking faults observed in the particles were interlaces between the hexalgonal oll and 411 (or cubic $.10^{\circ}$ ) phatses of the 
$\mathrm{SiC}$ material. Such stacking faults are not uncommon in $\mathrm{SiC}$ particles, and are frequently a result of variability in their fabrication process.

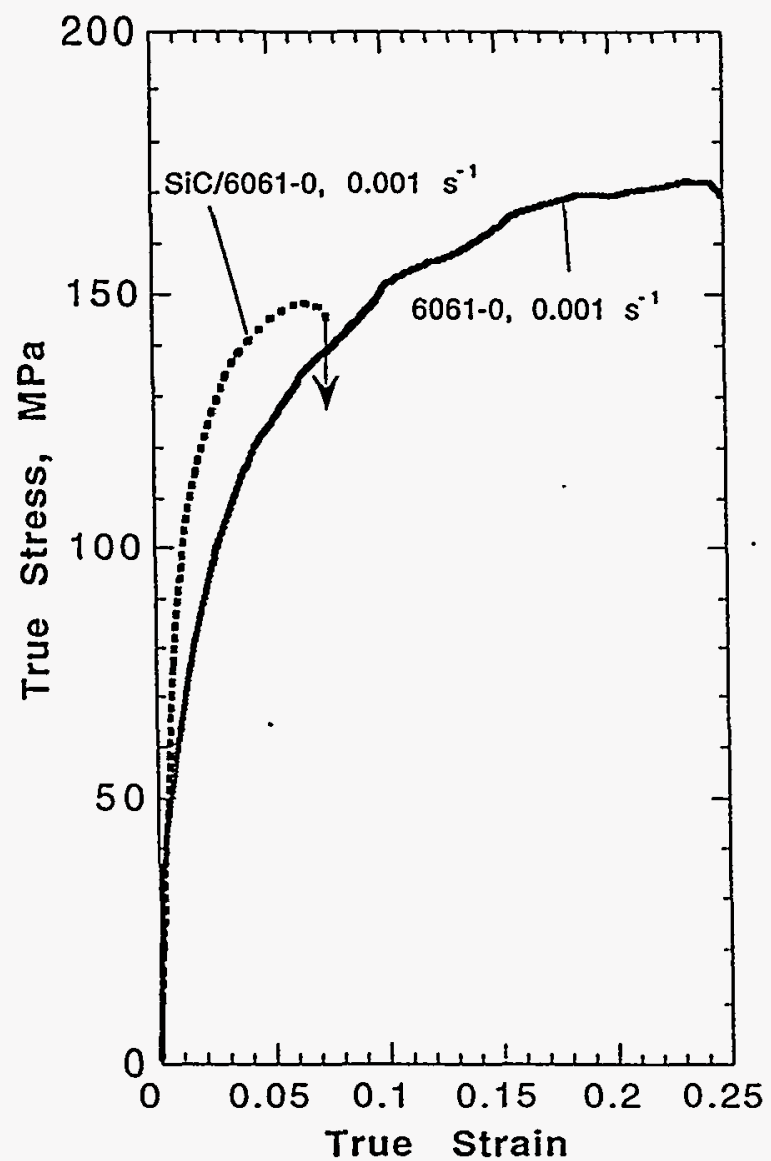

FIGURE 3. Low strain rate tension responses for the unreinforced 6061 alloy and $\mathrm{SiC} / 6061$ composite samples.

Particic fracture and debonding can occur in the carly stages of plastic deformation in the SiC compositc material as a result of stress concentration sites, and clastic discontinuitics in the particles. Particle fracture is detrimental to the strength. stiffness, and fracture toughness of these materials.

\section{CONCLUSIONS}

The strength of a $\mathrm{SiC}$ particle reinfored $\mathrm{Al}(6) 6 \mathrm{f}$ matrix compositc, measured in hoth compression and cension. was not signilicantly enhanced over that of the unceinforced alloy. This amomalous betalvior was allributed (1) partick-matris debondin: and particle cracking in the composite samples. While the poor particle/matrix debonding was due to poor particle-matrix wetting, the cause of particle cracking was the presence of stacking faults within the reinforcing particles.

Microcracks were observed to nucleate on these stacking faults. The stacking faults were preferred sites for crack propagation because of the material weakness across the stacking fault. It is important to account for these heterogenities when making strength predictions on such materials.

\section{ACKNOWLEDGMENTS}

The authors would like to thank Mike Lopez and Robert Carpenter of Los Alamos National Laboratories for their help with the experimentation.

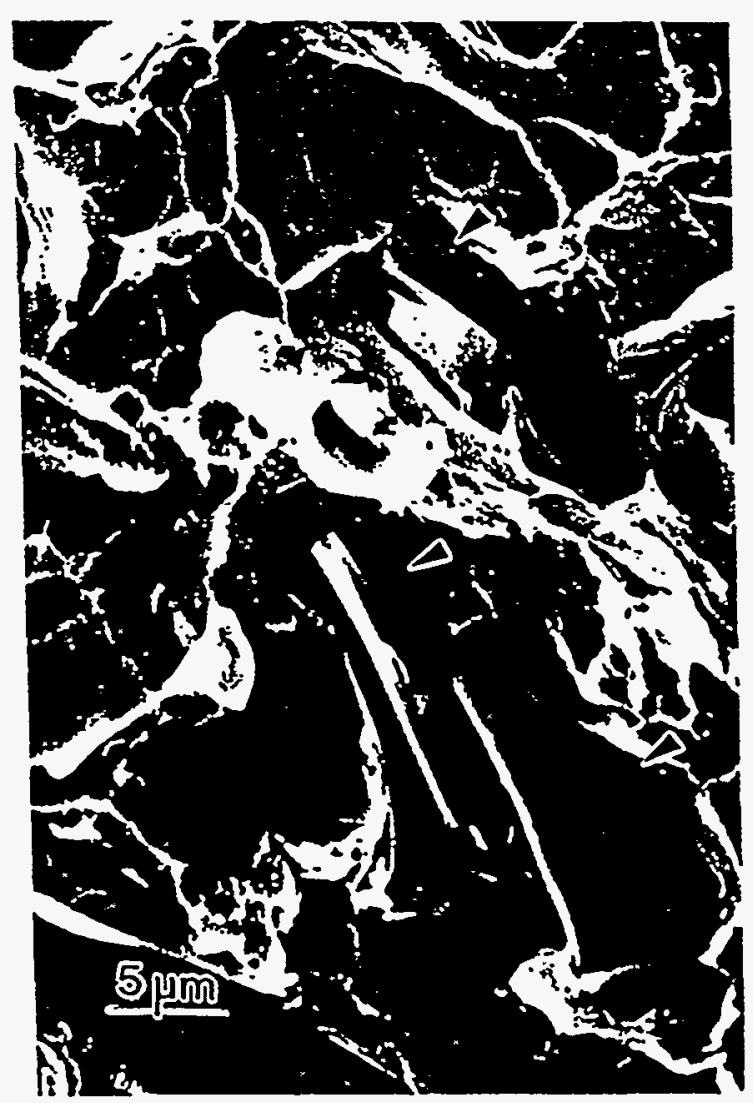

FIGiRE 4. Scamning electron micrograph of the fractured surface of the $S i c / 60)$ l composite illustrung cextensive particle-matrix dehonding. 


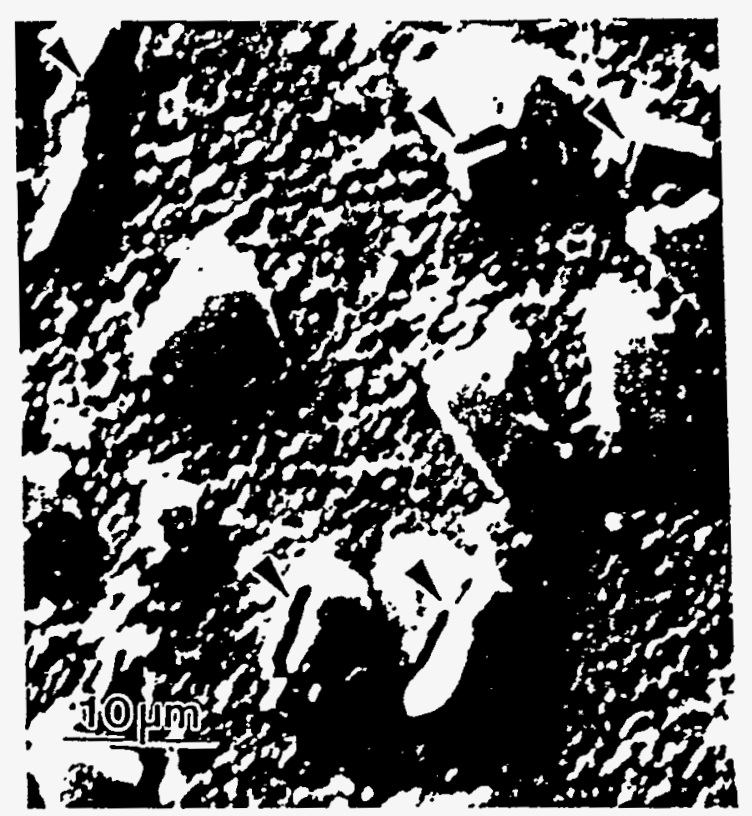

FIGURE 5: SEM micrograph of cracked $\mathrm{SiC}$ particles in the polished surface of a fractured sample.

\section{REFERENCES}

1. Arsenault R. J. and Wu S. B., Scripta metall.. 18 (1984) 925.

2. Arsenault R. J., Mater. Sci. Engng., 64 (1984) 171.

3. Arsenault R. J., Scripta metall., 22 (1988) 767.

4. Oh S. Y., Cornie J. A., and Russell K. C., Metall. Trans. A., 20 (1989) 527.

5. Ibid, idem, 20 (1989) 533.

6. Vaidya R. U., Song S. G., and Zurek A. K., Phil. Mag., 70 (1994) 819.

7. ASM Engineered Materials Handbook, 1991. Volume 4: Ceramics and Glasses, published by ASM International, Metals park, Ohio.

8. Song S. G., Vaidya R. U., Zurek A. K., and Gray G. T III , Metall. Trans., submitted.

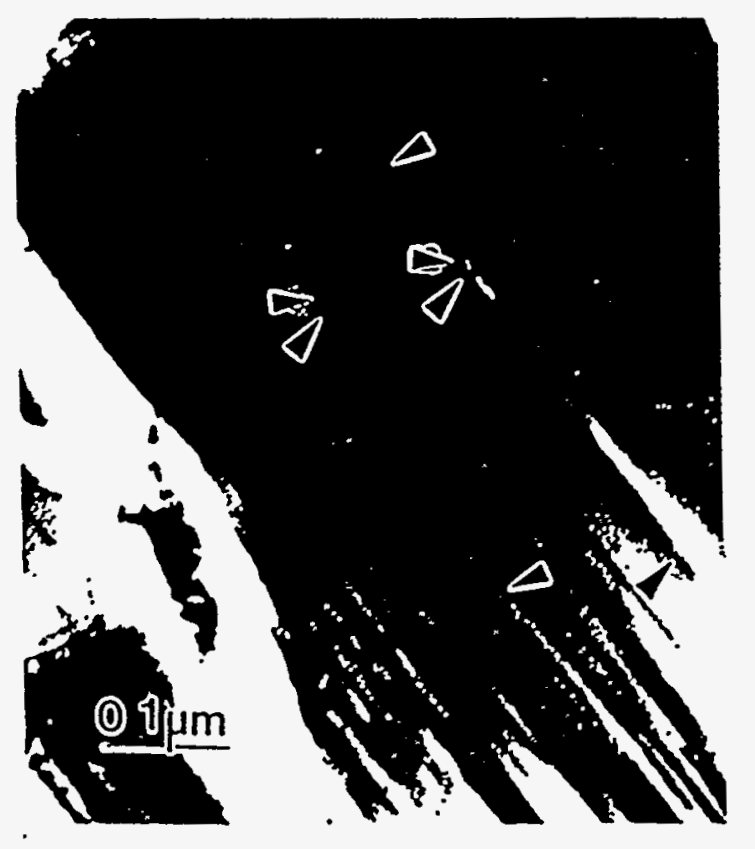

FIGURE 6. TEM micrograph of cracking within the $\mathrm{SiC}$ particles. Note that the cracks are parallel (o) the stacking faults within the particle

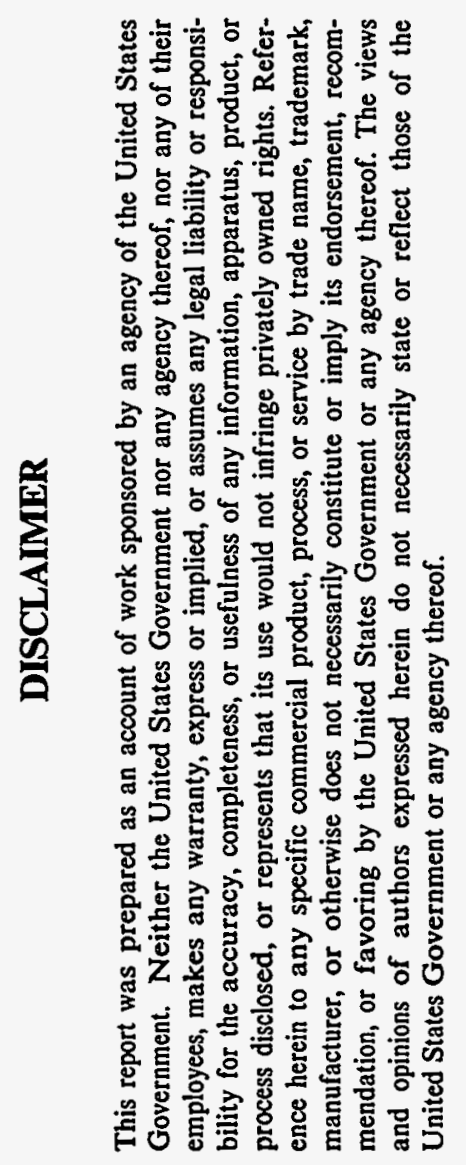

